\title{
O processo de ensino e aprendizagem de Limites em Assimilação Solidária
}

The teaching and learning process of Limits in Solidary Assimilation

Eduardo Rafael Zimdars ${ }^{1}$

Regina Helena Munhoz ${ }^{2}$

\section{Resumo}

Este artigo teve como objetivo analisar as possíveis influências da Pedagogia da Assimilação Solidária (AS) no processo de ensino e aprendizagem de Limites em uma turma de Cálculo I. A AS é uma proposta alternativa de ensino, contrapondo o ensino tradicional de matemática, proporcionando que os estudantes recebam bônus, em notas, pelo trabalho de aprendizagem realizado em grupo, sem relação com a nota da avaliação. O trabalho de aprendizagem se dá pelo tempo que o grupo permaneceu discutindo e resolvendo situaçõesproblema, sem considerar quantos problemas resolveu corretamente. Para determinar as formas de promoção e avaliação é necessário um contrato de trabalho, discutido e aprovado pela maioria dos estudantes de forma democrática. $\bigcirc$ trabalho de aprendizagem de cada aula é baseado em uma ficha de trabalho, composta por problemas sobre o tema abordado. Neste artigo, analisamos as atividades sobre limites, aplicada com 37 estudantes de uma turma de Cálculo I de uma universidade pública de Santa Catarina. Os dados foram compostos pela ficha de trabalho e pelas intervenções do professor-pesquisador durante a aplicação da proposta. Com os resultados percebemos que a intervenção foi satisfatória para a compreensão dos conceitos abordados e para autonomia de aprendizagem dos estudantes.

Palavras-chave: assimilação solidária; limites; intervenção em sala de aula.

\section{Abstract}

This paper aims to analyze the possible influences of the Solidarity Assimilation Pedagogy (SA) in the process of teaching and learning of limit in a classroom of Calculus I. The SA is an alternative proposal, in contrast to traditional mathematics teaching, allowing students to receive bonus grades for group learning work unrelated to the assessment grade. The learning work takes place by the time the group stayed discussing and solving problem situations, without considering how many problems it solved correctly. To determine the forms of promotion and evaluation, an employment contract is required, discussed and approved by many of the students, in a democratic way. The learning work of each class is based on a activity sheets composed of problems on the topic addressed. In this article, we analyze the activities of limits, applied with 37 students from a class of Calculus I of a public university in Santa Catarina. The data were composed by the activity sheets and the interventions of the

\footnotetext{
${ }^{1}$ Instituto Federal Catarinense | erzimdars@gmail.com

2 Universidade do Estado de Santa Catarina|rhmunhoz@gmail.com
} 
professor-researcher during the application of the proposal. With the results, we realized that the intervention was satisfactory for understanding the concepts addressed and for students' learning autonomy.

Keywords: solidarity assimilation; limits; classroom interventions.

\section{Introdução}

Segundo Vieira (2013), a escola "[...] se mantém no mundo contemporâneo sem sofrer grandes transformações" (p. 17). Essa frase inicial, nos permite perceber que em se tratando dos papéis da escola, ainda temos, enquanto sociedade, a concepção de uma escola tradicional, que é apenas responsável por transmitir e apropriar as novas gerações do conhecimento desenvolvido pela Humanidade. Mais do que isso, um espaço que privilegia a reprodução de ideias, sem críticas ou contraposições (VIEIRA, 2013).

Essa concepção de escola tradicional reverbera a imagem do professor que tem como objetivo transmitir conhecimento e do aluno que reproduz o que ouve. Paulo Freire (1987) chama esse sistema de "concepção bancária da educação, que objetiva depositar, transferir e transmitir valores e conhecimentos aos alunos" (Ibid., p. 59). Nesse sentido, o professor é o centro de todo o processo, enquanto os alunos são passivos e devem se adaptar às imposições. Em relação específica - não apenas - da Educação Matemática, D'Ambrosio (1989) entende que, nesse caso, a memorização e a repetição de exercícios são demasiadamente presentes no cotidiano das aulas. De modo que esse método faz com que os estudantes tenham uma visão limitada da importância da matemática.

[...] primeiro, os alunos passam a acreditar que a aprendizagem de matemática se dá através de um acúmulo de fórmulas e algoritmos. Aliás, nossos alunos hoje acreditam que fazer matemática é seguir e aplicar regras. Regras essas que foram transmitidas pelo professor. Segundo, os alunos acham que a matemática é um corpo de conceitos verdadeiros e estáticos, do qual não se duvida ou questiona, nem mesmo nos preocupamos em compreender porque funciona. Em geral, acreditam também, que esses conceitos foram descobertos ou criados por gênios (D'AMBROSIO, 1989, p. 16).

Ao encontro dessas críticas à escola e ao ensino tradicional, temos aquelas feitas por Baldino (1998), evidenciadas em Zimdars (2018), afirmando que se o objetivo da escola for a reprodução de ideias, existem outras opções disponíveis aos estudantes. Assim, hoje o estudante não depende, exclusivamente, do livro-texto, do material ou do conteúdo transcrito no quadro pelo professor, pois existem inúmeras outras opções, disponíveis online, que têm o mesmo objetivo. Como, por exemplo, as videoaulas dos mais renomados pesquisadores em áreas específicas do conhecimento, fazendo com que a "palestra" proferida pelo professor na sala de aula se torne obsoleta; as aulas de resolução de exercícios também estão disponíveis em quantidade numerosa na rede. Em relação específica ao ensino de matemática, ainda podemos citar a disponibilidade de softwares 
que auxiliam os estudantes na resolução de questões sobre aritmética, algébrica e, inclusive, gráfica, com softwares de geometria dinâmica.

Baldino (2001) chama essa concepção de Ensino Tradicional Vigente (ETV), caracterizado pela centralidade da aula no professor e no conteúdo e na avaliação da competência final adquirida pelo estudante, sem consideração do processo de aprendizagem. De acordo com o autor, é necessário o rompimento com o ETV, possibilitando que o estudante trabalhe colaborativamente o maior tempo possível para aprendizagem de algum conteúdo, sem que apenas ouça o professor falar e resolver exemplos. Para romper com o ETV umas das possibilidades é a chamada Pedagogia da Assimilação Solidária, proposta pelo professor Roberto Ribeiro Baldino, desde a década de 1980, proposta desse artigo.

Com base nisso, a pergunta norteadora dessa pesquisa é "como ocorre o processo de ensino e aprendizagem de limites de funções de uma variável real, por meio da Assimilação Solidária (AS), em uma turma de CDI I?". Tendo como objetivo de pesquisa analisar como ocorre o processo de ensino e de aprendizagem de limites por meio da AS. Para tanto, apresentaremos a AS, seus objetivos e princípios; a proposta desenvolvida para a turma de CDI I da Licenciatura em Matemática da UDESC, a metodologia adotada no artigo e para a análise dos dados; a discussão dos resultados, com base na literatura sobre o tema; finalizando com considerações sobre o estudo feito.

\section{Pedagogia da Assimilação Solidária}

A gênese da AS é a crítica ao ETV, ou seja, constitui-se como uma possibilidade de romper com o ensino tradicional de matemática. No ETV, como já mencionamos, o processo de ensino e aprendizagem é centrado no professor e no conteúdo, a memorização é a medida da aprendizagem. Além disso, para Baldino (1994, 1998), existe um contrato de trabalho implícito, mantendo professor e estudantes atuando conforme o sistema vigente.

Nesse sentido, espera-se, por meio desse contrato, que o professor tenha domínio do conteúdo ministrado, que o estudante participe com perguntas, frequente o mínimo de aulas exigido para aprovação e, principalmente, saiba resolver as questões da prova escrita. Em contrapartida, o aluno espera que o professor não registre suas ausências, o que muitas vezes ocorre; não exija que faça outras atividades além da prova; não faça perguntas. Porém, como este contrato é implícito, acredita-se que são aprovados apenas os que adquiriram o mínimo de conhecimentos necessários, ou seja, o único critério de aprovação é o desenvolvimento de conhecimento na disciplina em questão (BALDINO, 2001).

Dessa forma, Baldino (1998) e Silva (1997), quando propõem a AS, contestam o ETV afirmando que muitos dos alunos aprovados são aqueles que souberam se adequar ao contrato, as regras, sem relação direta com o conhecimento construído: "No ETV alardeia-se a preocupação com a injustiça de reprovar o aluno que sabe, exatamente para desviar a atenção da injustiça que mais se comete, ao aprovar o que não sabe" (BALDINO, 1995, p. 4). Também, a reprovação tem relação com a não adequação ao contrato implicitamente estabelecido.

Em oposição a este sistema temos a AS, uma proposta didático-pedagógica centrada em um contrato de trabalho explícito, aprovado de forma democrática pelos estudantes. Esse 
contrato, diferente do ETV, apresenta todos os critérios de avaliação e promoção em sala de aula, podendo ser modificado se a maioria quiser, com exceção de alguns itens substanciais à AS - caso sejam retirados retorna-se ao ETV. Desse modo, o ponto central é que paralelamente a avaliação escrita, o tempo de aprendizagem em grupo seja um critério avaliativo. Na AS "o foco da aprendizagem está no aluno, contrapondo o ETV, cujo principal foco é no conteúdo e no professor" (SILVA, 1997, p. 14). Desse modo, a sala de aula está em AS se houver: "[...] a medida da duração e a avaliação da qualidade do trabalho de aprendizagem como critério subsidiário de aprovação explícito, independente dos critérios de avaliação de conteúdo" (BALDINO, 2001, p. 2).

O trabalho de aprendizagem é o percurso que se faz para alcançá-la, mesmo que não se chegue ao nível que se espera: "O trabalho produtivo é medido por sua duração, não pela competência matemática atingida, nem pela extensão do assunto coberto (quantidade de exercícios resolvidos, número de páginas lidas, etc.)" (BALDINO, 1998, p. 13). A nota não é dada pelo resultado, mas pela quantidade de tempo despendida para estudar, em coletividade, um conteúdo, discuti-lo e, em partes ou totalmente, entendê-lo. Nesse sentido, a avaliação da AS retrata como o aluno trabalhou e como foi a postura do grupo perante a aprendizagem solidária (ZIMDARS, 2018).

Além disso, outros princípios são substanciais, como a escolha individual dos alunos em participarem ou não da proposta, evidenciando o aspecto democrático da AS. Isso significa que, conforme o contrato estabelece, a avaliação escrita ainda terá peso na nota do aluno, porém em conjunto com a nota dada pelo trabalho de aprendizagem. Logo, o aluno pode optar por ser avaliado apenas pela nota da avaliação. Caso participe da AS, o trabalho em sala deverá ser em grupos homogêneos em relação ao conhecimento no campo da disciplina, princípio também fundamental. Isso se faz necessário uma vez que na AS não se tem interesse em cobrir uma quantidade de conteúdos, mas permitir que os grupos discutam problemas que contribuam para construção de conhecimentos relacionados a disciplina (BALDINO, 2001).

Ademais, a postura do professor durante a aula também é um princípio inegociável, ou seja, ele atua como mediador das discussões dos grupos, questiona as afirmações e propõem revisões nos problemas e conclusões apresentadas. Esse princípio é resumido como "Aprende-se falando, ensina-se ouvindo" (BALDINO, 2001, p. 13). Assim, o professor permanece durante a aula atendendo os grupos de forma individual, apenas no final, caso seja necessário, resolve algum problema para a sala toda. Também, cabe ao professor, escolher os problemas/exercícios para as aulas, com base no conteúdo que pretende abordar. Esses problemas são apresentados na ficha de trabalho de cada aula, pela qual o professor avalia o desenvolvimento do grupo. Além das fichas de trabalho, cada aula da AS tem uma ficha de sugestões - composta por definições, indicação de bibliografia e exemplos - e uma ficha de respostas - resolução da ficha de trabalho, entregue ao final da aula (ZIMDARS, 2018).

Por fim, a supremacia dos grupos em relação aos indivíduos também é um princípio fundamental. Ele serve para garantir que as decisões sejam tomadas de forma democrática, sem que o professor faça acordos individuais com os estudantes. Nesse sentido, a participação é fundamental na AS, principalmente durante a plenária, momento destinado à discussão do trabalho do dia, modificações/votação das regras do contrato, demais assuntos que possam surgir. A plenária ocorre no final de cada aula, na qual cada participante pode 
propor modificações no trabalho, temas para as próximas aulas e fazer questionamentos sobre os problemas resolvidos. Sendo que cada modificação, após a discussão, deverá ser aprovada pela maioria presente (SILVA, 1997).

Outros critérios apresentados no contrato são negociáveis, ou seja, dependem das discussões e votações feitas em sala. Para que se entenda quais são estes itens, o leitor pode consultar o quadro 2. A partir dos princípios fundamentais e acordos estabelecidos democraticamente, os grupos recebem a cada aula da AS uma nota pelo trabalho de aprendizagem, que considera a observância dessas regras. Essa nota terá um peso na nota final do trabalho produtivo, que é escolhido por votação durante a plenária, limitando-o em $50 \%$.

\section{Proposta desenvolvida}

Como mencionado, a turma de CDI I do curso de Licenciatura em Matemática da UDESC foi o cenário de investigação para uma dissertação de mestrado, na qual foi proposta uma intervenção para o estudo de limites por meio da AS, com os princípios mostrados na seção anterior. Essa turma era composta por 37 alunos e foi dividida em equipes de 2 a 4 integrantes, formando 9 grupos no total. Esses grupos foram pré-selecionados pelo pesquisador com base na avaliação realizada na disciplina anteriormente, ou seja, foram criados três grandes grupos com base nas notas: grupo com notas iguais ou acima de seis, grupo com notas menores do que seis e grupo sem nota na primeira avaliação. A partir disso, sem infringir o princípio de homogeneidade da AS, os próprios estudantes puderam escolher seus grupos. Estes grupos foram nomeados por letras maiúsculas $(L, M, N, \ldots, T)$ e cada integrante pela letra e número, por exemplo, L1, R3 etc.

Conforme prevê a AS, em cada aula os grupos resolvem problemas sobre os conteúdos estudados, propostos pelo professor por meio da ficha de trabalho. Além da ficha de trabalho, em cada aula existe uma ficha de sugestões que indica caminhos e referências para auxiliar os grupos de trabalho nas resoluções e uma ficha de respostas utilizada no final da aula durante a plenária. Ao todo, foram trabalhadas oito aulas, de duas horas/aula cada, para o estudo de limites, das quais analisamos, especificamente, neste artigo, uma aula sobre limites calculados por meio de tabelas de valores.

As atividades utilizadas estão presentes na ficha de trabalho 2 - FT2, com o objetivo de trabalhar o tema apresentado. Para isso foram escolhidos quatro problemas. Os três problemas iniciais - A, B e C - apresentavam funções e pediam, por meio de quadros, que fossem feitas estimativas numéricas da imagem da função, quando $x$ se aproximava de um valor pela esquerda (valores menores) e pela direita (valores maiores). Já no problema D, tivemos uma aplicação de limites à cinemática, mais especificamente sobre a velocidade média e instantânea de um móvel. Os problemas são apresentados no quadro 1. 
Quadro 1: Questões da Ficha de Trabalho 2

A. Seja uma função $f: R \rightarrow R$, definida por $f(x)=3 x+1$

1. Esboce o gráfico dessa função.

2. Qual a imagem de $f$ quando $x=2$ ?

3. Sabemos que qualquer intervalo real é infinito, nesse sentido analise o que acontece na vizinhança do ponto $x=2$, com auxílio do quadro abaixo (inicie preenchendo os valores mais distantes de $x=2)$ :

\begin{tabular}{|c|c|c|c|c|c|c|c|c|c|c|c|}
\hline$x$ & 1 & 1,5 & 1,9 & 1,99 & 1,999 & $\mathbf{2}$ & 2,001 & 2,01 & 2,1 & 2,5 & 3 \\
\hline$f(x)$ & & & & & & & & & & & \\
\hline
\end{tabular}

O que acontece com $f(x)$ quando $x$ se aproxima de 2? Poderíamos aproximar $x$ ainda mais de 2? É correto afirmar que o limite de $f(x)$, quando $x$ tende a 2, é 7 ? Justifique e escreva esse limite por meio de símbolos.

B. Considere a função $g(x)=\frac{3 x^{2}-5 x-2}{x-2}, x \neq 2$. Determine a imagem de cada valor de $x$, conforme o quadro:

\begin{tabular}{|c|c|c|c|c|c|c|c|c|c|c|c|}
\hline$x$ & 1 & 1,5 & 1,9 & 1,99 & 1,999 & $\mathbf{2}$ & 2,001 & 2,01 & 2,1 & 2,5 & 3 \\
\hline$g(x)$ & & & & & & & & & & & \\
\hline
\end{tabular}

1. $O$ que acontece com $g(x)$ quando $x$ se aproxima de 2? Qual o limite de $g(x)$ quando $x$ tende a 2? Escreva esse limite através de símbolos.

2. O limite neste ponto é igual a imagem da função? Justifique.

3. Com base nessa questão e na anterior, qual a diferença entre elas?

C. Considere a função:

$$
h(x)=\left\{\begin{array}{lr}
x \quad \text { se } x \leq 2 \\
x-1 \quad \text { se } x>2
\end{array}\right.
$$

Determine a imagem de cada valor de $x$, conforme o quadro:

\begin{tabular}{|c|c|c|c|c|c|c|c|c|c|c|c|}
\hline$x$ & 1 & 1,5 & 1,9 & 1,99 & 1,999 & $\mathbf{2}$ & 2,001 & 2,01 & 2,1 & 2,5 & 3 \\
\hline$h(x)$ & & & & & & & & & & & \\
\hline
\end{tabular}

1. $\bigcirc$ que acontece com $h(x)$ quando $x$ se aproxima de 2? A aproximação pela esquerda (valores menores que 2) é igual a aproximação pela direita (valores maiores que 2)? Qual o limite de $h(x)$ quando $x$ tende a 2 ?

2. $\bigcirc$ limite neste ponto é igual a imagem da função? Justifique.

D. Considere a seguinte situação: Um objeto se move em linha reta segundo a função posição $S(t)=2 t^{2}+1$ em metros, t em segundos. Responda:

1. Qual a velocidade média do objeto no intervalo de tempo $[0,10]$ ?

2. Qual a velocidade média do objeto no intervalo de tempo $[0,5]$ ?

3. Qual a velocidade média do objeto no intervalo de tempo $[0,1]$ ?

4. Utilize a ficha de sugestões e calcule uma estimativa, através da ideia intuitiva de limite, para a velocidade instantânea do objeto no instante $t=1$ segundo.

5. Por que podemos dizer que essa é estimativa da velocidade instantânea em $t=1$ segundo?

6. Escreva formalmente o limite dessa função.

Fonte: dos autores, 2019. 
Além da análise da resolução dos problemas apresentada pelos grupos, a AS tem interesse nas relações estabelecidas entre os participantes, o professor e as regras do contrato de trabalho. Dessa forma, é igualmente importante, no contexto da AS, a análise da postura desses grupos em relação à observância das regras preestabelecidas. Os itens analisados nesse sentido são apresentados no quadro 2, que compôs o cabeçalho das fichas de trabalho.

Quadro 2: Regras da AS

$\rightarrow$ Itens individuais (X para sim): ( ) Faltou; ( ) Chegou atrasado; ( ) Saiu mais cedo; ( ) Não trouxe o material de consulta; ( ) Chamou o professor sem consentimento do grupo; ( ) Atrapalhou o rendimento do grupo; ( ) Não conhecia ou desrespeitou o contrato de trabalho; ( ) Falta de comprometimento com a aprendizagem.

$\rightarrow$ Itens do grupo: (marcar a quantidade de ocorrências ou X para sim): ( ) Nem todos os membros sabiam perguntar ou explicar o que já haviam feito; ( ) Não aguardaram a sua vez de atendimento; ( ) Trabalho feito de forma individual; ( ) Algum componente está atrasado ou adiantado em relação ao grupo; ( ) Consultaram a ficha resposta antes de finalizar a atividade;

( ) Tempo de efetivo trabalho (medido em horas).

Fonte: dos autores, 2019.

\section{Percurso metodológico}

A metodologia adotada durante o processo é qualitativa (BOGDAN; BIKLEN, 1994). Em relação aos procedimentos, é uma pesquisa participante (GIL, 2008), na qual o pesquisador e os investigados atuam de forma conjunta, contribuindo no processo como um todo.

Os dados coletados foram as resoluções das atividades presentes na ficha de trabalho conforme quadro 1-, a observância das regras preestabelecidas no contrato de trabalho conforme quadro 2 - e a interação entre os estudantes e o professor-pesquisador, durante o atendimento aos grupos e na plenária. Para analisarmos estes dados utilizamos a análise de conteúdo, proposta por Bardin (1977). Segundo, Santos e Dalto (2012), diversos professores e pesquisadores têm desenvolvido seus trabalhos com base na exploração da produção escrita dos alunos. O objetivo dessa metodologia é "a construção de inferências sobre seus conhecimentos, em processos recursivos de construção de unidades de análises e categorizações" (SANTOS; DALTO, 2012, p. 2).

Assim, após a análise a priori, dividimos os dados em duas categorias, conforme o quadro 3. A primeira, categoria $\lambda$ : observância das regras da AS pelos grupos de trabalho, com base no exposto no quadro 2. A segunda, categoria $\varphi$ : resolução total ou parcial da ficha ${ }^{3}$, com as subcategorias $\varphi 1$ : problemas resolvidos corretamente, $\varphi 2$ : problemas resolvidos parcialmente corretos e $\varphi 3$ : ficha totalmente errada. Ressaltamos que essas subcategorias foram utilizadas para analisar os problemas que efetivamente foram resolvidos, uma vez que para a AS não importa a quantidade de questões feitas.

\footnotetext{
${ }^{3}$ De acordo com a análise, nenhum grupo deixou a ficha totalmente em branco, por isso não consideramos essa possibilidade na categoria.
} 
Quadro 3: Categorias e Subcategorias de Análise

\begin{tabular}{|c|c|}
\hline Categorias & Subcategorias \\
\hline $\begin{array}{c}\text { A- Observância das regras da AS pelos } \\
\text { grupos de trabalho }\end{array}$ & - \\
\hline$\varphi-$ Resolução total ou parcial da ficha & $\varphi 1$ problemas resolvidos corretamente \\
\hline & $\varphi 2$ problemas resolvidos parcialmente corretos \\
\hline
\end{tabular}

Fonte: dos autores, 2019.

\section{Resultados e discussão}

Nesta seção apresentamos os dados e suas respectivas análises. Para isso, conforme a descrição da metodologia de análise dos dados, temos duas categorias, $\lambda$ e $\varphi$, que são analisadas nos itens seguintes, assim como os dados gerais da aula. Para fins de contextualização vale ressaltar que na presente aula tivemos a presença de 33 alunos, formando as seguintes equipes: uma dupla, quatro trios e cinco equipes com quatro integrantes.

\section{Regras da AS - Categoria $\lambda$}

Em relação as regras da $A S$, os grupos $O, Q, S$ e $T$ infringiram a regra de trabalho colaborativo, realizando algumas questões de forma individual. Percebemos isso analisando de forma minuciosa as conclusões discrepantes que integrantes de um mesmo grupo tiveram. É importante ressaltar que isso ocorreu de forma pontual, ou seja, a FT2 foi, em sua maioria, realizada de forma conjunta pelos estudantes.

Por exemplo, a equipe $\mathrm{Q}$ realizou trabalho individual apenas no problema C. O grupo iniciou o trabalho de forma colaborativa, mas na questão 2 desse problema tivemos duas respostas distintas. Enquanto o participante Q1 concluiu que o limite no ponto é igual a imagem, o participante Q2 respondeu "não, pois o limite bilateral não existe" (participante de pesquisa, 2017).

Essa regra, conforme Baldino (2001) e Zimdars (2018), é importante para garantir que o grupo discuta os problemas da ficha de trabalho e busque estratégias de resolução com base em referências sobre o tema, ou seja, os problemas devem ser do grupo e não do indivíduo. Dessa forma, o professor deve ser chamado quantas vezes o grupo julgar necessário, mas com a condição de que todos saibam explicar o que foi resolvido até o momento e qual a dúvida da equipe.

Ademais, todas as regras da AS foram satisfeitas por todos os grupos, ao menos pelos indícios da FT2. Com isso, entendemos que, se comparada com a aula anterior, na presente aula tivemos dados mais positivos em relação a proposta da AS. Segundo Baldino (1998), inicialmente os alunos têm dificuldades em se adaptar a um sistema contrário ao ETV, o que com o tempo de aplicação vai sendo modificado.

Além disso, é importante destacar que nesta aula uma das equipes definidas no início da intervenção solicitou, com argumentos de que o trabalho não estava sendo produtivo, a modificação do grupo. Desse modo, o professor-pesquisador consentiu, uma vez que já havia percebido esse aspecto na última aula. Essa modificação não infringiu a regra da 
homogeneidade dos grupos, pois a escolha de outros grupos pelos três participantes dessa equipe não foi aleatória.

\section{Desenvolvimento Matemático - Categoria $\varphi$}

A análise dessa categoria foi feita com base nos problemas presentes na FT2, conforme quadro 1. Na categoria $\varphi$, que classifica os grupos de acordo com os problemas que foram resolvidos, percebemos que três grupos $(\mathrm{L}, \mathrm{O}$ e $\mathrm{U}$ ) finalizaram todos os problemas - de forma correta ou incorreta, enquanto que os demais deixaram alguns itens em branco. Sobre os acertos e erros nas resoluções, tivemos a classificação conforme o quadro 4.

Quadro 4: Classificação dos grupos nas subcategorias de $\varphi$

\begin{tabular}{|c|c|}
\hline Subcategoria & Grupos \\
\hline$\varphi 1$ problemas resolvidos corretamente & $L, M, N, P, R, S, U$ \\
\hline$\varphi 2$ problemas resolvidos parcialmente corretos & $\mathrm{O}, \mathrm{Q}, \mathrm{T}$ \\
\hline$\varphi 3$ ficha totalmente errada & nenhum grupo \\
\hline
\end{tabular}

Fonte: dos autores, 2019.

As equipes $L$ e $U$ resolveram toda a ficha corretamente, apresentando a simbologia adequada e concluindo de forma coerente as questões. Consideramos como resoluções corretas aquelas que, baseadas em conceitos do cálculo, tanto mais formais quanto intuitivos, conseguissem explicar o que estava acontecendo com as funções quando o valor de $x$ se aproximava do valor analisado.

As demais equipes dessa subcategoria não finalizaram totalmente a ficha. Assim, tivemos alguns grupos, a saber $\mathrm{P}, \mathrm{R}$ e $\mathrm{S}$, que realizaram todas as questões corretamente também, mas sem concluir totalmente o problema $\mathrm{D}$. Os grupos $\mathrm{M}$ e $\mathrm{N}$ realizaram corretamente todos os problemas, porém deixaram em branco o problema $\mathrm{D}$.

Já na subcategoria $\varphi 2$, a equipe $O$ resolveu todos os problemas, porém errou alguns. Fizeram corretamente o problema A, já no problema B erraram a conclusão, dizendo que "O limite será diferente de 7, pois quando $x=2$ é indeterminado. Mas observando a tabela vemos que quanto mais próximo de $x=2$ a imagem é próxima de 7" (01, sujeito de pesquisa, 2019). 0 que notamos é que mesmo com o quadro de valores feito de forma correta, figura 1, a equipe não entendeu que para o limite existir o ponto pode não estar definido no domínio da função.

O professor-pesquisador sugeriu, na aula seguinte, que a equipe consultasse materiais de apoio e comentou sobre o problema conceitual que tiveram, uma vez que na AS o seu papel é verificar, por meio das fichas, as inconsistências que os estudantes apresentam nas resoluções. Já no problema $\mathrm{C}$ o grupo $\mathrm{O}$ fez apenas o primeiro item, que indagava sobre $\mathrm{O}$ que acontecia com as aproximações laterais em um ponto, visto que a função era definida por partes. Novamente, preencheram o quadro de forma correta, porém não souberam interpretar que os comportamentos eram distintos, à esquerda e à direita, concluindo que o limite existia. A equipe não iniciou o problema D. 
Figura 1: Desenvolvimento do Problema B, participante 01

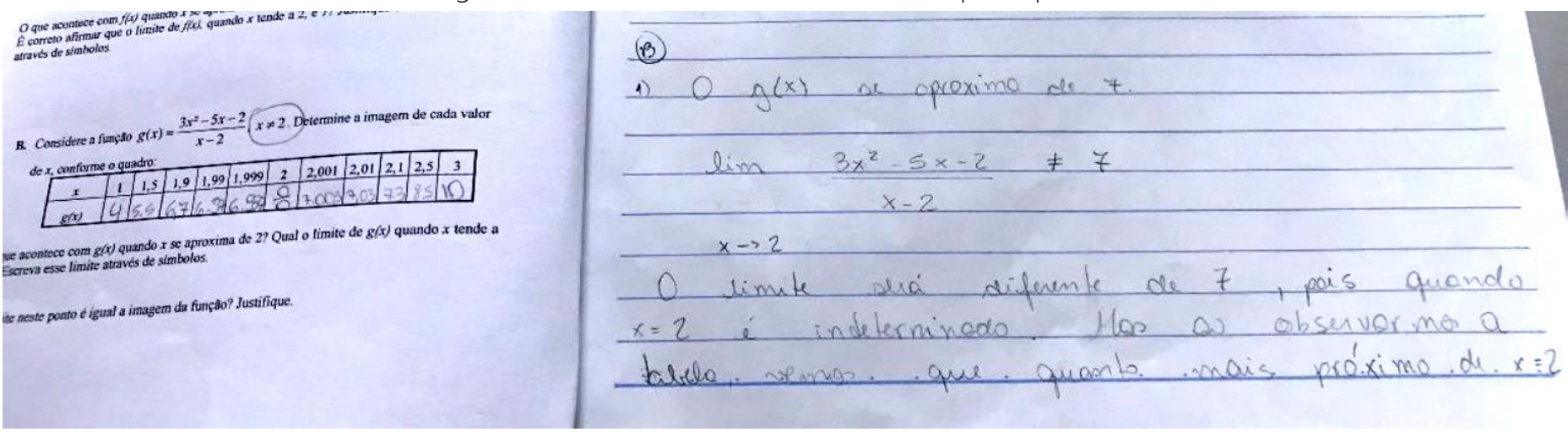

Fonte: dados de pesquisa, 2019.

Na mesma subcategoria ainda estava o grupo T, que resolveu a FT2 até o item 1 do problema $\mathrm{C}$, porém com respostas incompletas. Além disso, este grupo não se atentou a nomenclatura correta, usando termos incoerentes para descrever a situação. Um exemplo disso é na resolução do problema B, no qual a equipe não conseguiu, na resposta dada, relacionar a ideia de aproximação com o valor do limite da função. A figura 2 mostra isso. Por fim, a dupla Q não fez o problema D, resolveu alguns itens de forma individual, o que ocasionou o fato de um dos integrantes (Q1) errar o item dois do problema C e o outro integrante (Q2) acertar, como vimos na análise anterior.

Figura 2: Desenvolvimento do Problema B, participante T4.
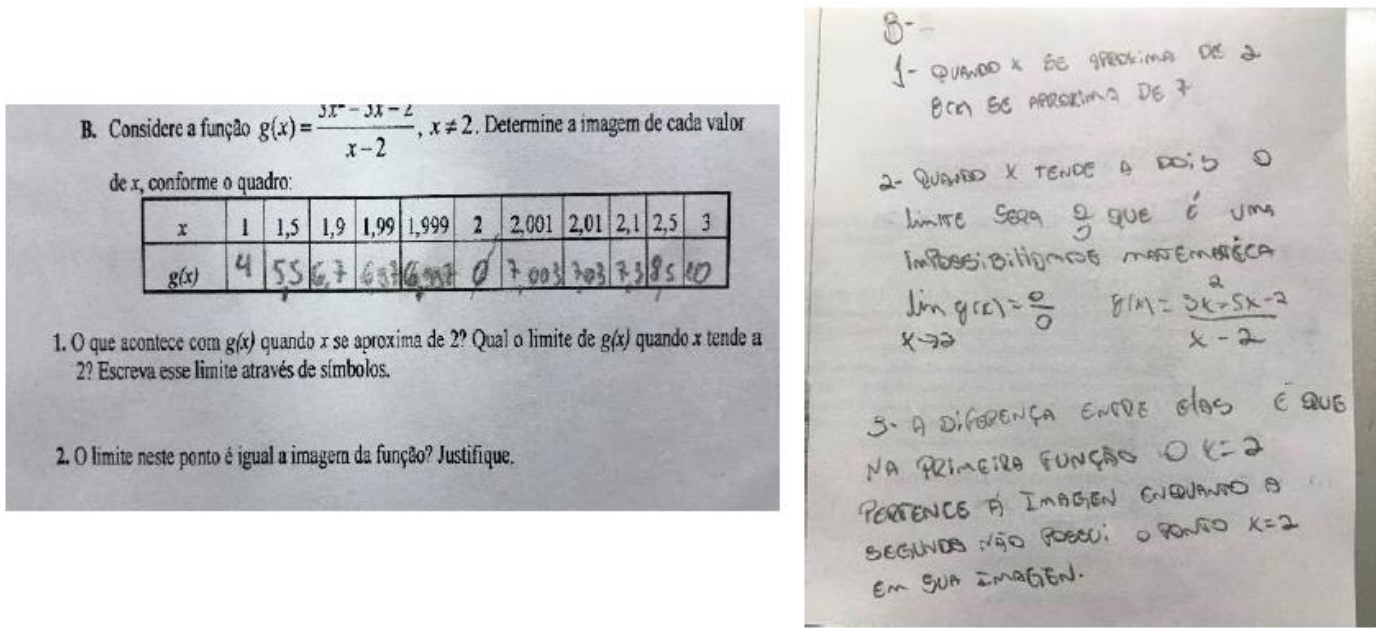

Fonte: dados de pesquisa, 2019.

Para melhorar o desenvolvimento desse grupo e dos demais, além do uso das demais FT, esperávamos que participassem do Ensino Remedial, a fim de realizarem mais problemas, verificando inconsistências nas suas concepções. Ademais, de forma geral os grupos tiveram um desempenho bom no desenvolvimento da FT2, inclusive melhor do que na FT1. Esse fato pode ser interpretado, segundo Baldino (1994), sobre dois pontos de vista, os quais foram verificados durante a intervenção. O primeiro é que os alunos se familiarizam com o passar do tempo com a AS e, o segundo, que a integração entre os grupos também aumenta com 
o tempo. Assim, entendemos que esses dois aspectos melhoraram o rendimento dos integrantes.

\section{Plenária}

A plenária teve início nos 20 minutos finais da aula, iniciando pelo retrospecto dos problemas resolvidos. No que tange os problemas, o professor-pesquisador os abordou com base no desenvolvimento geral dos grupos e suas dificuldades, usando a ficha de sugestões, composta por exemplos de limites de funções. Os grupos participaram respondendo às perguntas feitas. Nesse momento percebemos, segundo relato de alguns grupos, que eles acabaram lendo a ficha de sugestões apenas no final da aula, tendo dificuldades para resolver a FT2. Com isso, entendemos que se tivessem lido no início, conforme orientação, teriam mais facilidade nos problemas. Sobre isso, fora enfatizado a importância de utilizar o material de pesquisa, tanto a ficha de sugestões, mas também outros materiais (livros, softwares) que podem ampliar a visão dos grupos em relação aos problemas.

Após o retrospecto, durante a plenária, que é aberta para todos os alunos exporem opiniões, fazerem perguntas ou colocações, alguns grupos pediram que o problema $C$, da cinemática, fosse novamente abordado, pois não tiveram tempo de finalizar ou erraram. 0 professor-pesquisador explicou que as FT anteriores devem ser resolvidas ou refeitas extraclasse, com auxílio da ficha de respostas, uma vez que para a AS os estudos feitos durante as aulas não são suficientes. Desse modo, enfatizou a importância do Ensino Remedial para a AS. Por fim, votou-se o peso da AS do dia que variou entre $20 \%$ e 50\%, sendo escolhido pela maioria o peso de $40 \%$ em relação a nota final.

\section{Considerações finais}

Retomando o objetivo do presente artigo - analisar como ocorre o processo de ensino e de aprendizagem de limites por meio da AS - podemos tecer algumas considerações. Nesse sentido, torna-se evidente que a AS, durante toda a proposta, modifica tanto as relações entre os indivíduos da sala de aula quanto a relação entre eles e o conhecimento. Entendemos que a proposta central da AS é evidenciar o contrato implícito do ETV, os seus artifícios e farsas. Assim, é importante perceber que ela não é um rompimento com o conteúdo estudado, mas com a forma que se avalia o desenvolvimento do estudante, sendo sua promoção proporcional ao trabalho desenvolvido.

Desse modo, em nossa intervenção, evidenciou-se que a AS, mais do que o ETV, não isenta o estudante de suas obrigações de estudar, pesquisar e discutir os conteúdos abordados. Por isso, a AS fracassa, como qualquer outra proposta, quando o estudante não assume esse papel. A diferença percebida é que a AS garante que o estudante será avaliado apenas pelos critérios do contrato, sem apropriação do trabalho alheio e sem relação direta com a quantidade de conteúdos estudados ou exercícios feitos.

Por conta desses fatores, entendemos que a comparação da AS com os critérios do ETV, no qual apenas o resultado é considerado, não é possível. Uma vez que no ETV a quantidade de questões feitas é a mensuração do conhecimento desenvolvido, sem relação com o que foi estudado e discutido em grupo. Enquanto na AS, o mais importante são essas discussões 
e a superação de dúvidas que os grupos apresentavam acerca de conteúdos abordados nas fichas.

Além disso, no contexto da proposta, percebemos que em relação ao conteúdo abordado o professor-pesquisador pode verificar inconsistências pontuais em cada grupo de trabalho, uma vez que permaneceu durante toda a aula circulando pelos grupos. Um dos aspectos mais importantes, nesse sentido, é que alguns grupos tiveram problema em reconhecer o limite como ideia de aproximação, pela esquerda e pela direita, para um mesmo valor $f(x)$. Em contrapartida, tinham a ideia de que o limite sempre seria igual a imagem da função naquele ponto. Isso permitiu que direcionássemos nossas ações para superar essas dificuldades, mas que, novamente, dependiam da participação ativa dos estudantes.

Um dos recursos da AS, para auxiliar nessa superação, é o Ensino Remedial, cujo objetivo é formalizar os conteúdos/conceitos abordados na ficha de trabalho, que não foram totalmente compreendidos, com mais intervenções do professor. Porém, percebemos que diversos participantes entenderam esse momento como uma monitoria, na qual o aluno resolve exercícios sem a intervenção do professor, sendo que temos como hipótese que esse fato fez com que o Remedial fosse pouco frequentado, mesmo com o bônus da nota. Essa perspectiva acarretou para a concepção equivocada de ele não é uma parte importante da AS - mesmo aspecto analisado na intervenção relatada por Silva (1997). Levando o estudante a concluir "[...] que o Remedial é um mero detalhe, ou seja, um problema de ordem secundária que poderá ser superado no momento oportuno" (SILVA, 1997, p.55). Entretanto, entendemos que com o tempo de implementação da AS esses aspectos sejam superados, os artifícios do ETV se tornem menos expressivos, a interação entre os grupos seja maior e a participação no Ensino Remedial e os estudos extraclasse se incorporem a rotina dos estudantes.

Por fim, compreendemos que com a intervenção, foi possível recuperar o diálogo nas aulas de matemática, importante para o entendimento de conceitos. Também, fazer com que os estudantes sejam responsáveis pelo seu desenvolvimento, permitindo que, com o auxílio e mediação do professor, sejam mais autônomos. 


\section{Referências}

BALDINO, R.R. Assimilação Solidária onze anos depois. Grupo de Pesquisa-Ação em Educação Matemática. Unesp: Rio Claro, 1994.

BALDINO, R.R. Assimilação Solidária. Grupo de Pesquisa-Ação em Educação Matemática. Unesp: Rio Claro, 2001.

BALDINO, R.R. Assimilação Solidária: escola, mais-valia e consciência cínica Educação em Foco, Juiz de Fora, Editora da UFJF, v.3, n. 1, p. 39-65, mar. /ago. 1998.

BALDINO, R.R. Normas da Assimilação Solidária. Grupo de Pesquisa-Ação em Educação Matemática. Unesp: Rio Claro, 1995.

BARDIN, L. Análise de conteúdo. Tradução: Luís Antero Reto, Augusto Pinheiro. São Paulo: Edições 70, 1977.

BOGDAN, R.C; BIKLEN, S.K. Investigação Qualitativa em Educação: uma introdução a teoria e aos métodos. Portugal: Porto Editora, 1994.

D’AMBROSIO, B. Como Ensinar Matemática Hoje? SBEM, Brasília, ano 2, n.2, p.15-19, 1989.

FREIRE, P. Pedagogia do Oprimido. Rio de Janeiro: Paz e Terra, ed. 17, 1987.

SANTOS, J.R; DALTO, J.O. Sobre a análise de conteúdo, análise textual discursiva e análise narrativa: investigando produções escritas em matemática. Anais do V seminário internacional de pesquisa em Educação Matemática. Rio de Janeiro, 2012.

SILVA, M.R.G. Avaliação e trabalho em grupo em assimilação solidária: análise de uma intervenção. Rio Claro, 1997. Tese (Doutorado) - Universidade Estadual Paulista.

VIEIRA, A. F. Ensino do Cálculo Diferencial e Integral: das técnicas ao humans-with-media. 2013. 204 f. Tese (Doutorado) - Faculdade de Educação, Universidade de São Paulo, São Paulo, 2013.

ZIMDARS, E.R. Pedagogia da Assimilação Solidária: Desafios e Possibilidades no Processo de Ensino e Aprendizagem de Limites. 203 f. Dissertação (Mestrado) - Pós-graduação em Ensino de Ciências, Matemática e Tecnologias, Universidade do Estado de Santa Catarina, Joinville, 2018. 